\title{
Documenting the Indian response to Covid-19: too little, too soon
}

\author{
VIJAYAPRASAD GOPICHANDRAN
}

\section{Chandrakant Lahariya, Gagandeep Kang, Randeep Guleria. Till we win: India's fight against the COVID-19 pandemic. Penguin Random House India, Gurgaon, 2020, 352 pgs, Rs 299, ISBN: 9780143451808.}

The Indian Journal of Medical Ethics had commissioned a review of this book and sent me a copy on October 7, 2021, after a previously invited reviewer was unable to complete it. As I started reading it, the preface gave me the feeling that this book was about the Indian "success story" in controlling the pandemic. Take for example this paragraph in the Introduction:

However, against the grim projections, India has reported COVID-19 cases and deaths far below every 'disease modelling' estimate made in the earlier stage of the pandemic. It is partly indicative of the success of the many interventions undertaken, but there's no denying the upheavals we have faced.

The book was published in November 2020, and I am writing this review in October 2021. So, I was concerned that the review may not be relevant, as much water has flowed under the bridge over the past year. Since the publication of the book, we have survived a second wave of the pandemic which was catastrophic in proportion and took a huge toll of life. I have reviewed the book from the perspective of a reader who wants to understand the "Indian response" to the first wave of the Covid-19 pandemic in the country.

In the first section titled "Understanding the Challenge", the authors provide an excellent overview of emerging and reemerging infections and why new infections have the potential to become pandemics. Some information, like the fact that there are $1.25 \times 10^{23}$ viruses per human being on this

Author: Vijayaprasad Gopichandran (vijay.gopichandran@gmail.com) Assistant Professor, Department of Community Medicine, ESIC Medical College and PGIMSR, KK Nagar Chennai 600078 INDIA.

To cite: Gopichandran V. Documenting the Indian response to Covid-19: too little, too soon. Indian J Med Ethics. Published online on October 20, 2021.DOI: 10.20529/IJME.2021.080

(c) Indian Journal of Medical Ethics 2021 planet, are interesting and likely to grab the readers' attention. The details about SARS-CoV2, its structure, how it spreads and attacks the human cells have been described well, and in a manner that is easy to understand.

The second section titled 'Mounting a Response' is where I started feeling uncomfortable with the narrative. I felt the presentation was not balanced and the narrative took on a self-righteous tone from this point onwards. For instance, there is a chapter on the lockdown and its impact. However, there is a fleeting mention of the haste with which it was ordered (1), and this is overshadowed by the description of the benefits of a lockdown. It also fails to report the unscientific activities that were encouraged by the government, such as lighting of lamps, banging of plates, etc., which seemed to defy logic (2), and ended up creating crowds of people literally celebrating the arrival of Covid-19! Conspicuous by its muted presence in the book is the plight of the thousands of migrant workers with no recourse but to move back to their hometowns, mostly on foot; or of the way they were treated, like hordes of infectious animals at the points of entry into their home states (3). While these are not things that the state can be proud of, they are important facts that cannot be erased from the pages of history. While the section describes clearly the various public health interventions including testing, contact tracing, isolation, treatment, it does not mention the immeasurable suffering that people endured because of all this. It does not cover the heavy policing and police violence that happened in the name of enforcing a lockdown (4).

The chapter titled "The Undaunted Human Spirit: Stories from the Frontline" is a very inspiring note on the work of frontline workers and healthcare providers who did a tremendous job during the pandemic. It is very important to acknowledge the contributions of the underdogs of the public health machinery in India, the accredited social health activist or ASHAs, the auxiliary nurse midwives or ANMs, the anganwadi workers and sanitary workers. This chapter does that sincerely. However, while celebrating their contributions on one hand, and honouring the martyrs, it is also important to document how the health system failed them in so many ways, which this section ignores. There were many instances of failure to protect healthcare workers in the frontline from violence, instances where the deceased healthcare providers were not even allowed to be cremated in public crematoria (5), and resident doctors and nurses' protests because of not receiving 
their salaries. The irony of one paragraph titled "India, a country of and built by internal migrants" (p 135), moved me to tears. One line in this paragraph is "The story of migrants is also that of resilience". Most of us reading this review are people of privilege and so are most who have read or will read the book. Sitting comfortably in our armchairs sipping a hot beverage, we can comment on "stories of resilience". But they were first stories of desperation, hunger, pain, humiliation, and misery, before they became stories of resilience. When a description skips all the former stories and rushes to the latter, it does injustice to them and their condition during the pandemic.

Section three of the book is titled "Science, Solidarity and Hope". The scientific facts are very well explained. The chapters in this section provide good evidence-based summaries of various treatments and the process of evidence generation itself. It traces the story of Hydroxychloroquine and how it became a magical remedy early on during the pandemic and the controversies surrounding it, and completes the story with how it was removed from most Covid-19 treatment guidelines on being proven ineffective. It also clearly mentions the lack of effectiveness of Remdesivir, convalescent plasma, and various repurposed drugs. The Covid-19 vaccines were not yet ready when this book was published and hence the chapter on vaccines is theoretical and describes the various types of vaccines and vaccine candidates. It is useful to read as it provides a clear understanding of the vaccine development process. However, the chapter underplays the media frenzy surrounding Remdesivir and convalescent plasma (6), despite very poor evidence to support these treatments. The chapter does not focus on the fact that many pharmacies, hospitals, and black marketers profited from the desperation of people who thronged the pharmacies to purchase Remdesivir. While it is important to acknowledge that pharmaceutical and therapeutic research has taken place on an unprecedented scale in the past two years during the pandemic, it is equally important to recognise that these two years have seen the worst abuse of prescription practices and antimicrobial use, and has thrown evidence-based medical practices to the backburner. These aspects are absent in this section.

The fourth and last section of the book is titled "Getting Future Ready" and is the most important contribution of this book. It outlines the various measures to be taken to strengthen the health system in India to make it resilient and ready to face future pandemics. The suggestions are clear and explained well. There are some very strong recommendations such as effective risk communication with active community engagement, evidence-based policy making, data-based monitoring, and over and above all, comprehensive strengthening of the health system across all levels. This chapter frames the Covid-19 pandemic as an opportunity to understand and strengthen the health system and expansion of universal health coverage. These are very positive messages and will likely leave a strong impact on policy makers.

Overall, when I finished reading the book, I was left with a sense of confusion. Is this a book about the "successes" of India's pandemic response? It probably is not, because even though it does mention this "success" in many places and hints at it in others, the book was written between the two waves and India stumbled under the intensity of the disastrous second wave. Is this a historical documentation of India's public health response to the pandemic? It is probably not, because it is incomplete, and not balanced. Is it a common-person's textbook of Covid-19, its prevention, and strategies to recover from it safely? Though it does provide a lot of scientific information in simple language, which is easy to understand and precise, it has also provided inaccurate social narratives which misrepresent the reality. I closed the book, removed my glasses, and pondered, "Maybe they should have written this book after the second wave, probably after all subsequent waves, to completely document the Indian response to the pandemic? Was too little written, too soon?"

\section{References}

1. Zee News Bureau. PM Modi places India under 21-day lockdown to fight coronavirus: What is open, what is not. Zee News. 2020 Mar 25[cited 2021 Oct 18]. Available from: https://zeenews.india.com/ india/pm-modi-places-india-under-21-day-lockdown-to-fightcoronavirus-what-is-open-what-is-not-2271485.html

2. Bhaskar U. PM Modi calls for 9-minute blackout on Sunday, urges citizens to light lamps. Live Mint. 2020 Apr 3[cited 2021 Oct 18]. Available from: https://www.livemint.com/news/india/pm-modicalls-for-9-minute-blackout-on-sunday-urges-citizens-to-lightlamps-11585886215053.html

3. Choolayil AC, Putran L. The COVID-19 pandemic and human dignity: the case of migrant labourers in India.J Hum Rights Soc Work. 2021 Jul 13[cited 2021 Oct 18]: 1-12. Doi: 10.1007/s41134-021-00185-x. Available from: https://www.ncbi.nlm.nih.gov/pmc/articles/ PMC8276029/

4. Reuters. Indian police use violence against coronavirus lockdown offenders. Reuters. 2020 Mar 5[accessed 2021 Oct 18]. Available from: https://www.reuters.com/video/watch/idOVC6K2RMZ

5. Kengadaran S, Divvi A, Kengadaran S. Violence among healthcare workers during COVID-19 pandemic in India. J Family Med Prim Care. 2021 Feb 27; 10(2): 1066-7.Doi: 10.4103/jfmpc.jfmpc_2054_20

6. Ghosh S. COVID-19: Treatment via plasma, remdesivir may just be keeping hopes alive. New Indian Express. 2021 May 24[cited 2021 Oct 16], Available from: https://www.newindianexpress.com/nation/2021/ may/24/covid-19-treatment-via-plasma-remdesivir-may-just-bekeeping-hopes-alive-2306748.html 